Bull, Mater. Sci., Vol. 4, Number 3, May 1932, pp. 369-373, (C) Printed in India.

\title{
Some notes on the first Spacelab payload
}

\author{
J M HAYNES \\ Department of Chemistry, University of Bristol, Bristol, UK \\ MS received 17 June 1980
}

The Space Shuttle, when it is laurched on its twelfth orbital flight (due in September 1983), will carry in its cargo bay the Spacelab laboratory, equipped for its first operational mission. In this brief teview, the scientific objectives and the composition of the Spacelab payload for the first flight will be examined, and an indication will be given of the cost of putting an experiment into orbit.

Spacelab itself is wholly European in design and construction. It has been produced under the auspices of the European Space Agency (ESA), with the active participation of nine countries-Germany, Belgium, Denmark, Spain, France, Great Britain, Italy, Netherlands and Switzerland-with Austria also taking part as an observer. The prime contractor for its fabrication is the German aerospace concern ERNO, of Btemen. About 50 other European companies are also directly involved. The total outlay is some US $\$ 600$ million over the period 1973-80 with Germany financing more than half of the programme (table 1).

The Spacelab configuration for the first flight will comprise two modules and a short pallet. The two modular segments will provide a cylindrical working space, $4 \mathrm{~m}$ in diameter and $5.4 \mathrm{~m} \mathrm{long}$, for the conduct of manned experiments, while unmanned experiments will be mounted outside on the pallet. This configuration can provide $22 \mathrm{~m}^{3}$ of experiment volume within the module with a mass limit of 4.6 tonnes. In fact, the total mass of the first Spacelab experiment payload is

Table 1. Distribution of European funding of Spacelab development programme $(\%)$

\begin{tabular}{lr} 
Germany & $53 \cdot 3$ \\
Italy & $18 \cdot 0$ \\
France & $10 \cdot 0$ \\
United Kingdom & $6 \cdot 3$ \\
Belgium & $4 \cdot 2$ \\
Spain & $2 \cdot 8$ \\
Netherlands & $2 \cdot 1$ \\
Denmark & $1 \cdot 5$ \\
Switzerland & $1 \cdot 0$ \\
Austria & $0 \cdot 8$ \\
& \\
& 100 \\
\hline
\end{tabular}


only about $2 \cdot 8$ tonnes, and the available power is also restricted, since a major function of the first mission is systems verification and the actual conduct of experiments must be subjugated to this end.

During the week-long flight of the first Spacelab mission, about 100 man-hours of work will be devated to the scientific programme. The scientific tasks will far the most part be carried out by the two payload specialists, one European and one American. The other four crew members (commender, pilot and two mission specialists, all American), although concerned with other duties, will be familiar with the objectives and operation of at least some of the experiments.

The five-man team from which the two payload specialists will be chosen for the first flight has been under training since mid-1978. Those not selected for the first flight will go as crew members on later missions. The training of the payload specialists is both wide-ranging and intensive, since their performance in orbit may be the ultimate factor in determining the success or failure of each experiment. Each payload specialist must be familiar not only with the functions and operation of every instrument in the space laboratory, but must also understand thoroughly the scientific goal and background of each experiment. Their training programme therefore includes a series of seminars and discussions with the principal investigators associated with all the experiments, and visits to most of their laboratories throughout Europe and North America.

The first Spacelab payload (FSLP) will comprise 76 scientific and technological experiments involving 219 investigators from 16 countries. The majority of the experiments (60 in all) are of European arigin. Their distribution amangst the seven areas of scientific study defined for the first mission is shown in table 2 .

Table 2. European component of FSLP.

\begin{tabular}{|c|c|c|c|c|}
\hline $\begin{array}{l}\text { Area of } \\
\text { study }\end{array}$ & $\begin{array}{l}\text { Number of } \\
\text { experiments }\end{array}$ & Instruments & Participating countries & Location \\
\hline $\begin{array}{l}\text { Atmospheric } \\
\text { Physics }\end{array}$ & $3)$ & \multirow{4}{*}{$\begin{array}{l}\text { Telescopes and } \\
\text { Spectrometers }\end{array}$} & (Germany, Belgium, France & Pallet \\
\hline Solar Physics & 2 & & Belgium & Pallet \\
\hline Plasma Physics & 3 & & $\begin{array}{l}\text { Germany, Austria, France, } \\
\text { Norway }\end{array}$ & Pallet \\
\hline Astronomy & 2 & & $\begin{array}{l}\text { Germany, France, UK, } \\
\text { Italy }\end{array}$ & Pallet \\
\hline $\begin{array}{l}\text { Earth } \\
\text { Observation }\end{array}$ & Two groups & $\begin{array}{l}\text { Metric camera : } \\
\text { Microwave scattero- } \\
\text { meter }\end{array}$ & Germany & \\
\hline Life Sciences & 10 & Vestibular sled & $\begin{array}{l}\text { Germany, France, UK, } \\
\text { Italy, Sweden, } \\
\text { Switzerland }\end{array}$ & Module \\
\hline $\begin{array}{r}\text { Materials } \\
\text { Science }\end{array}$ & 40 & $\begin{array}{l}\text { Fluid Physics Module : } \\
\text { Furnaces (gradient, } \\
\text { isothermal and mirror) }\end{array}$ & $\begin{array}{l}\text { Germany, Austria, } \\
\text { Belgium, Denmark, } \\
\text { Spain, France, UK, } \\
\text { Italy, Netherlands, } \\
\text { Sweden }\end{array}$ & Module \\
\hline
\end{tabular}


About one-fifth of the experiments will be carried on the pallet and are intended to take advantage of the good viewing conditions outside the earth's dense atmasphere. The remainder, comprising life sciences and materials science experiments, will be carried inside the module. All these experiments depend on the prolonged microgravity offered by Spacelab. Materials science experiments outnumber all others in the ratio $2: 1$.

The forty materials science experiments of European origin in ESLP fall mainly into the broad subject-areas of crystal growth, solidification of alloys and glasses, and fluid physics, including surface phenomena and capillarity. Clearly, the major advantage here is in the suppression of gravity-driven convection and sedimentation effects and the promotion of surface phenomena.

Most experiments in this group are accommodated in the Materials Soience Double Rack (MSDR), which contains three types of equipment :

(i) common support equipment,

(ii) general purpose multi-user facilities, and

(iii) special equipment.

The cammon support equipment includes such facilities as power supplies, vacuum and inert gas lines, and coolant loops, together with work benches, sample storage ohambers and so on. It also includes a central control consale for overall contral and monitoring of experiment status, and a link to various data acquisition and transmission systems.

The general-purpose multi-user facilities provide the means for several independent investigators to conduct experiments without unnecessary duplication of basic equipment. Such multi-user facilities are an isothermal furnace, gradient furnaces providing controlled linear temperature profiles at both high and low temperatures and a low-power high-temperature mirror furnace, praviding appropriate thermal environments for a wide range of experiments in metallurgy, ceramios and crystal growth. The fluid physics module (described in more detail elsewhere in this volume) will enable several investigators to study liquid behaviour under weightlessness by application af mechanical, thermal and electrical disturbances of various kinds. Multi-user facilities of this kind have generally been developed and supplied by industrial consortia in response to requirements stated ariginally by the experimenters themselves, under contracts placed by ESA. It is intended that they should be available for use by other experimenters on later flights, possibly modified in such a way as to enable their operation independently of the MSDR.

Finally, the special equipment of the MSDR consists of various facilities dedicated to individual, largely autonomous, experiments. These include investigations of vapour and solution growth of organic crystals, capillary instability and hysteresis, adhesion of metals under ultra-high vacuum, and electrolysis under weightless conditions. Equipment of this kind has usually been developed and built by the investigators themselves.

Some personal observations on Spacelab from the user's point of view may be in order at this point. In particular, the cost of the Spacelab programme should be weighed against its likely benefits, not only for the general community but also for the user and his science. Such questions may be especially pertinent to materials science, which has hitherto been regarded, perhaps, as a relatively inexpensive field of study. 
The cost of the Space Shuttle programme is very high by any standard, but its potential benefits are perceived largely in terms that do not permit any reliable calculation of the return on the investment. Since, however, the Space Shuttle does not exist sclely as the vehicle for Spacelab, but bas many other functions, it can probably be assumed that its development would have taken place whether or not a scientific application was in view.

Given the existence of the Shuttle and its potential to carry a manned laboratory into orbit and return it to earth repeatedly, then the next question concerns the scientific value of such a facility. The unique features of the orbital environment, such as weightlessness and negligible atmospheric mass above the orbit, are wellknown. Their realization tbrough the Spacelab system offers additional advantages in the form of manned experimentation, large volume, reusability and rapid turn-round time, allowing more coherent development than is possible with 'single shot' experiments. Nevertheless, US $\$ 600$ million being spent over eight years on the development and construction of Spacelab is a large sum of money when compared with budgets of many programmes of scientific research-although it cannot be assumed that any large fraction of this sum would have been spent on terrestrial science had it not been devoted to Spacelab. As with the Shuttle, Spacelab's existence may be taken for granted, since the decision to build it was taken at a level that precluded any effective consultation with the scientific community.

The remaining question, then, concerns the potential value of Spacelab to an individual investigator. In certain ways, Spacelab offers experimental conditions that cannot be duplicated terrestrially and correspondingly there are numerous experiments that cannot be done in any other way than in crbit. Spacelab was intended originally to provide cheap and easy access to space research for a much broader spectrum of experimenters than hitherto ; nevertheless, for many of the FSLP investigators this will probably be the most difficult and costly experiment of their lives.

The cost of performing a Spacelab experiment can be considered under two headings, associated with equipment development and with the launch and implementation of the mission, respectively.

The development cost of the MSDR (at 1978 prices) is estimated to be US $\$ 19.7$ million, or, for an all-up mass of $467 \mathrm{~kg}$, US $\$ 42,200$ per kilogram. Of course, this is an overall average cost and individual elements oan deviate very far from the mean. For example, the development and construction of the autonomous capillarity module has been carried out at the University of Bristol for about one-tenth of this cost, since it is simple in design and uses a bigh proportion of off-the-shelf components. This overall cost for the MSDR is fairly typical of various major payload items for the first Spacelab mission, and it is a factor fifteen times lower, per kilogram, than the average cost of developing experimental packages for free-flying unmanned satellites such as Meteosat and HEOS. This difference arises partly from the presence of multi-user facilities, which seem to have intrinsically lower development costs than individual experiments, and partly because the environmental test requirements for Spacelab, thou gh still quite elaborate, are less stringent than for free-flying experiments.

Mission implementation costs include all activities from the delivery of the experimental equipment for integration to the return of data and samples to the 
investigator for analysis. For European participation in FSLP, the mission implementation cost is estimated to be about US $\$ 27.1$ million for a mass of $1392 \mathrm{~kg}$, or about US $\$ 19,500$ per kilogram. This does not include the Shuttle launch cost : in the case of the first Spacelab mission, whose primary function is to verify the Shuttle + Spacelab system, the experiments in FSLP amount to a. kind of bonus. For subsequent Spacelab flights, the cost of NASA launch services (in the region of US $\$ 30$ million per launch) will have to be shared among the experimenters, pro-rated on the basis of either mass or volume depending on which is the critical parameter for a given launch. However, this will not add to the cost of flying unit mass or volume, since the available payload will become considerably larger after FSLP.

The cost in time to each experimenter cannot be igncred, since even quite simple equipment can soon become rather elaborate when the needs for $100 \%$ reliability and strict safety must be met within the constraints of low mass, low power consumption and adequate strength to withstand the stresses of launch and re-entry. Designing an experiment to acceptable standards can be surprisingly time-consuming.

In addition, the planning of experiments in this unfamiliar environment will often necessitate a great deal of supportive terrestrial research, both theoretical and experimental. Quite often, such work might not otherwise be done. There has already been a considerable volu me of valuable work that has been stimulated merely by the prospect of conducting experiments in space. This has led, for example, to an improved understanding of convective phenomena and of the stability of rotating fluid masses, which will be of value far beyond the context of space research. These benefits would be credited to the space programme even if Spacelab were never to fly.

Despite the sums of money involved, it would probably be incorrect to conclude that the Spacelab venture marks the entry of the hitherto relatively humble subject of materials science into the ranks of 'big science', alongside high-energy particle physics, radioastronomy and so on. The difference lies in the potentially larger number of smaller experimenters that can become involved during the series of Spacela $b$ flights.

Whether such experiments will, in fact, be forthcoming depends to a great extent on the scientific value of results to be obtained from the initial flight. It is certain that the FSLP materials science experiments could not have been done in any other way and all the investigators concerned are confident that the results will be of lasting value. 